\title{
ON HEINZ-KATO TYPE CHARACTERIZATIONS OF THE FURUTA INEQUALITY II
}

\author{
C.-S. LIN
}

Abstract. This paper is a continuation of the previous one [8]. Here we show that it is still possible to have several characterizations of the Furuta inequality in terms of different types of the Heinz-Kato inequality. Some application are given.

Mathematics subject classification (1991): 47A30, 47A62, 47A63.

Key words and phrases: Heinz-Kato inequality, Furuta inequality, positive operator, polar decomposition, Löwner-Heinz inequality, $p$-hyponormal operator.

\section{REFERENCES}

[1] T. FuRUTA, $A \geqslant B \geqslant O$ assures $\left(B^{r} A^{p} B^{r}\right)^{1 / q} \geqslant B^{(p+2 r) / q}$ for $r \geqslant 0, \quad p \geqslant 0, q \geqslant 1$ with $(1+2 r) q \geqslant p+2 r$, , Proc. Amer. Math. Soc. 101 (1987), 85-88.

[2] T. FURUTA, An elementary proof of an order preserving inequality, Proc. Japan Acad. 65 (1989), 126.

[3] T. FuRUTA, Generalization of Heinz-Kato theorem via Furuta inequality, Operator Theory 62 (1993), 77-83.

[4] T. FurutA, An extension of the Heinz-Kato theorem, Proc. Amer. Math. Soc. 120 (1994), 785-787.

[5] M. FuJII, C. HimeJI AND A. MATSUMOTO, Theorem of Ando and Saito for p-hyponormal operators, Math. Japon. 39 (1994), 595-598.

[6] E. HeINZ, Beiträge zur Störungstheorie der Spektralzerlegung, Math. Ann. 123 (1951), 415-438.

[7] T. KaTo, Notes on some inequalities for linear operators, Math. Ann. 125 (1952), 208-212.

[8] C.-S. LiN, On Heinz-Kato type characterizations of the Furuta inequality, Nihonkai Math. J., (to appear).

[9] K. TANahashi, Best possibility of the Furuta inequality, Proc. Amer. Math. Soc. 124 (1996), 141-146. 